Copyright (C 2014 IEEE. Personal use of this material is permitted. Permission from IEEE must be obtained for all other uses, in any current or future media, including reprinting/republishing this material for advertising or promotional purposes, creating new collective works, for resale or redistribution to servers or lists, or reuse of any copyrighted component of this work in other works. 


\title{
Overload Prevention in an Autonomous Microgrid using Battery Storage Units
}

\author{
Megha Goyal, Student Member, IEEE, Arindam Ghosh, Fellow, IEEE and Farhad Shahnia, Member, IEEE
}

\begin{abstract}
A new control strategy for smooth transition of a battery storage unit (BSU) is proposed in this paper to prevent overloading in an autonomous hybrid microgrid. The BSU is controlled to come online to prevent overloading to the distributed generators (DGs) in the autonomous microgrid and to go offline when the load demand is less than the total rating of the DGs in the microgrid. The microgrid can contain either inertial DG or non-inertial DGs, which are controlled in a frequency droop. The sensing of switching on and switching off of the BSU depends on the frequency signal, which is developed in the paper. The proposed strategy is validated through PSCAD/EMTDC simulation studies.
\end{abstract}

Index Terms-Microgrid, Battery Storage Unit, Frequency Droop, Power Sharing.

\section{INTRODUCTION}

$\mathrm{I}_{\mathrm{N}}^{\mathrm{N}}$ $\mathrm{N}$ remote rural and energy deficient areas, micro electric power systems containing photovoltaic generation systems, wind generators, micro-gas turbines, etc. based Distributed Generators (DG) are attractive choices. A microgrid that has both inertial and non-inertial DGs is called a hybrid microgrid. Such micrgrids can deliver clean and renewable power close to customers' end in comparison of conventional power generation [1-2].

A microgrid can be connected to grid or can be isolated from the power grid [3]. For an autonomous microgrid, if total load demand plus losses exceed the combined available power of all DGs then overloading of DGs can occur. Thus, to prevent the overloading and to maintain reliability, Battery Storage Units (BSU) are viable options [4].

In an autonomous microgrid, control of real and reactive power is essential to maintain frequency and voltage within specified limits. The real and reactive power output of a generator can be independently controlled by changing the voltage angle (based on frequency) and the magnitude, respectively [5-6]. Therefore, frequency and voltage droop controls are the most common methods used for sharing real and reactive requirements of the load.

BSUs provide an added degree of freedom to an autonomous microgrid that allows reliable operation while obviating the need of large capital investment in terms of new DG procurement and connection. Moreover, a BSU on standby also allows for a certain amount of immediately available power to reduce the need for idling or lightly loaded DGs [7].

The authors thank the Australian Research Council (ARC) for the financial support for this project through the ARC Discovery Grants DP 0774092 and DP110104554.

M. Goyal is with Queensland University of Technology, Brisbane, Australia. A. Ghosh and F. Shahnia are with Curtin University, Perth, Australia (megha.goyal@student.qut.edu.au)
It has been shown in [8] that dispatchable DGs in an autonomous hybrid microgrid can share power in the ratio of their rating, even in the presence of plug and play of nondispatchable DGs, under the assumption that the peak load demand is less than the total rating of the all dispatchable DGs. Since the non-dispatchable DGs are not operational all the time, the DGs size selection should be made in such a way that dispatchable DGs are able to meet the total peak power demand. This however is a difficult proposition since the peak load keeps on increasing. Resizing of existing DGs is not an option. Therefore every autonomous microgrid must be equipped with some storage devices that can quickly come online when peak load exceeds the total generation of DGs.

In this paper, a new control strategy for smooth transition of a BSU is proposed to prevent the overloading of distributed generators (DGs) in an autonomous hybrid microgrid.

\section{MICROGRID STRUCTURE}

The autonomous microgrid structure under consideration is shown in Fig. 1. It is comprised of two DGs and a BSU. One of the DGs is a diesel generator (DGEN), while the other one is a microturbine (MT) [9]. The BSU nominally floats on the microgrid bus neither consuming nor supplying power [10 12]. It can then come online quickly without any substantial transient. The DGs supply a balanced passive load and share it in proportion to their respective ratings [13-14]. In Fig. 1, the real and reactive powers drawn/supplied are denoted by $P$ and $Q$. The real and reactive power supplied by $\mathrm{DG}_{i}$ are denoted by $P_{i}$ and $Q_{i}$. The real and reactive power demands of the load are denoted by $P_{L}$ and $Q_{L}$. The parameters of the DGs are given in Appendix A.

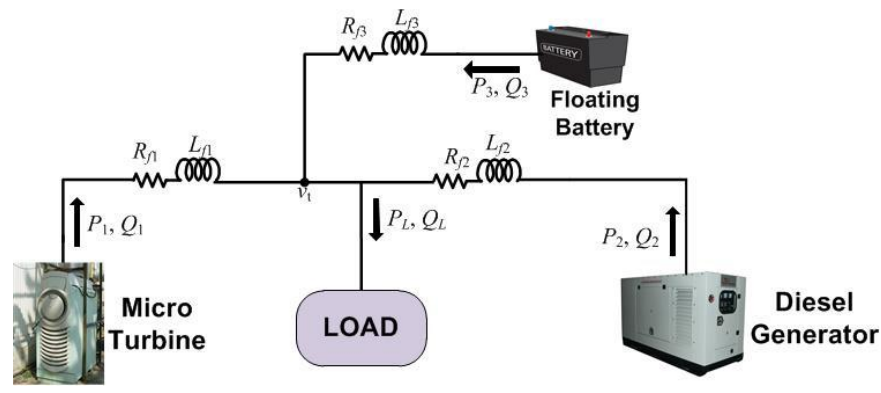

Fig. 1. Hybrid microgrid structure under consideration.

\section{EFFECT OF DGs OVERLOADING IN AN AUTONOMOUS MICROGRID}

DGs in the microgrid are controlled through a frequency droop, given by [15]

$\omega=\omega_{r}+m \times\left(0.5 P^{*}-P\right)$ 
where $\omega_{r}$ and $\omega$ are the rated and instantaneous frequency of the system, respectively.

Dispatchable DGs (inertial and non-inertial type) in an autonomous hybrid microgrid can share the power according to their rating using frequency droop control. However, if the load requirement is higher than the total rating of the DGs, some catastrophic failure will occur in the system. The following example illustrates this.

Example 1: Let us consider the system of Fig. 1, where the DGEN has a rating of $500 \mathrm{~kW}$ and the MT has a rating of 250 $\mathrm{kW}$. The droop parameters of the DGs are chosen such that the frequency excursion is limited to $\pm 0.3 \mathrm{~Hz}$ from the nominal value of $50 \mathrm{~Hz}$. This means that when DGs are not supplying any power, the frequency will be $50.3 \mathrm{~Hz}$ and the frequency will become $49.7 \mathrm{~Hz}$ when DGs are supplying $750 \mathrm{~kW}$.

First let us assume that the total load demand is $600 \mathrm{~kW}$ and both DGs are supplying power according to their rating (i.e. $2: 1)$. At $t=8 \mathrm{~s}$, the load is increased to $800 \mathrm{~kW}$, which is beyond the total rating of the DGs. The load, MT and DGEN real powers are shown in Fig. 2. When the power demand from the MT exceeds its rated power of $250 \mathrm{~kW}$, its output power is saturated by the actuator (fuel rate) limit at $250 \mathrm{~kW}$. In this case, the DGEN releases its stored kinetic energy to supply the load demand. As the overloading persists, the system wide voltage collapse occurs at around $11.9 \mathrm{~s}$, as seen in Fig. 3. This forces the powers to become zero as well (Fig. 2). The frequency of the DG calculated from (1) is shown in Fig. 4. Before the load change, the frequency of the system is 49.8 Hz. However, while the droop frequency is limited to $49.7 \mathrm{~Hz}$, the actual frequency of DGEN is reduced beyond the lower band in order to supply the excess power. This frequency keeps on dropping till the voltage collapse occurs, as seen in Fig. 5.

\section{PREVENTION OF DGs OVERLOADING IN AN AUTONOMOUS MICROGRID}

In the case of a microgrid, DGs overloading can be prevented by the help of BSUs. Below the developed control algorithm of the BSU is discussed. In an autonomous microgrid, system frequency differs from $50 \mathrm{~Hz}$ depending on the load. However, the frequency should not deviate more than \pm 0.3 Hz. With this band of frequency, proper droop gain of DGs can be chosen from (1) as discussed in [15].

From the droop gains chosen, it is obvious that the maximum power plus losses that can be supplied by the DGs is equal to their total rating. The frequency of the system becomes $49.7 \mathrm{~Hz}$ at this point from (1). According to this, lower threshold of $49.72 \mathrm{~Hz}$ is chosen. When the droop frequency hits this lower threshold, it implies that DGs are supplying their maximum available power to the load. When the load is increased, droop frequency crosses this lower threshold value and demonstrates that the DGs are overloaded. Comparing the actual system frequency and its lower threshold, a signal can be generated to turn on the battery. It is very crucial for the battery to come online very quickly. So artificial neural network (ANN) based controller is presented in [16] to control the BSU but it has a complicated design.

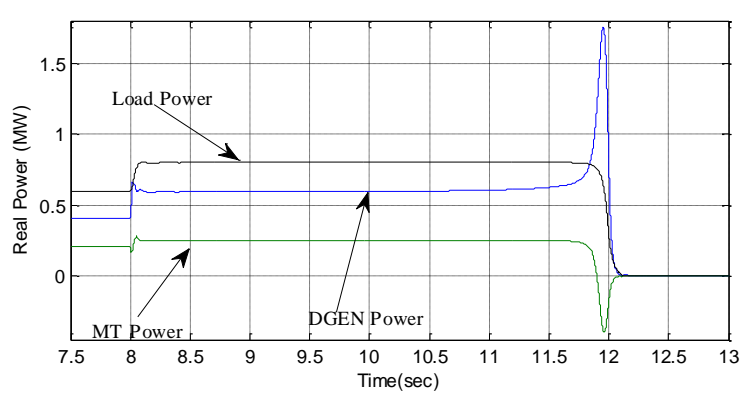

Fig. 2. Real power sharing between MT and DGEN in Example-1.

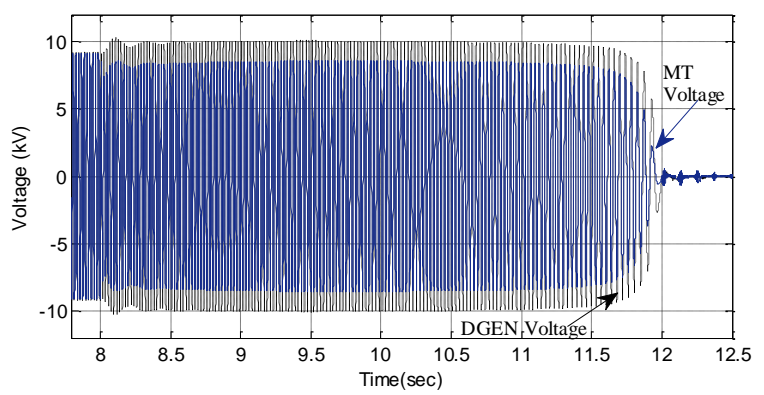

Fig. 3. Voltage of MT and DGEN terminals in Example-1.

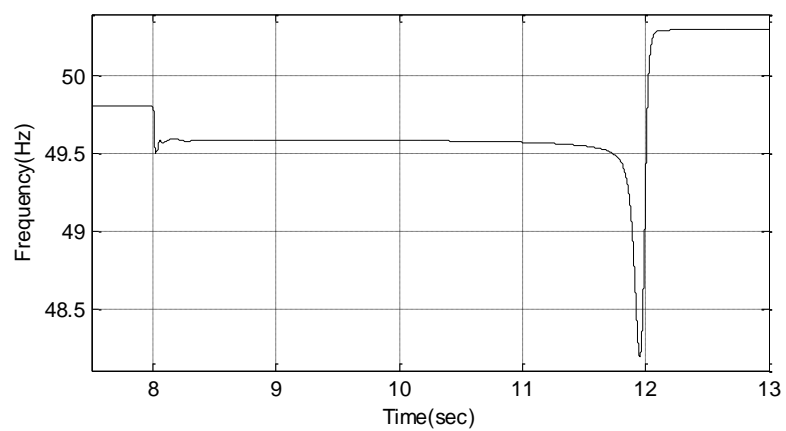

Fig. 4. Frequency variation of DG calculated from (1) in Example-1.

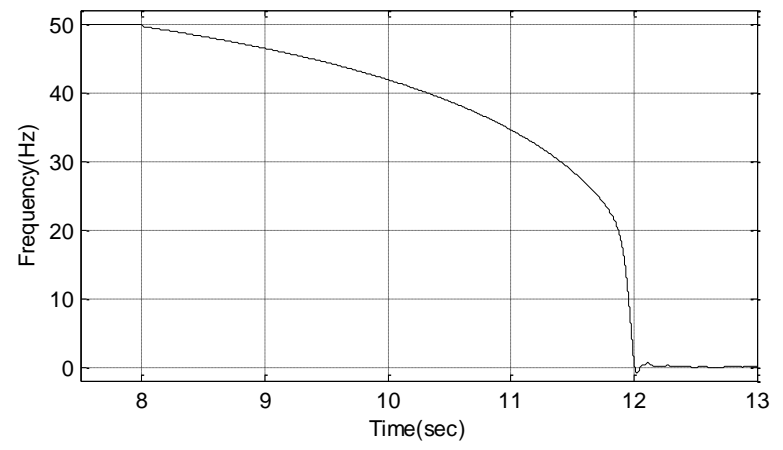

Fig. 5. Diesel generator frequency variation in Example-1.

In the microgrid structure shown in Fig. 1, DGs are inertial and pseudo inertial type. So there is sufficient time to turn on the battery. Once BSU turns on, it supplies its rated power and the rest of the load demand is supplied by the DGs in the ratio of their ratings. This implies that, the droop frequency will rise above the threshold value.

As the load demand reduces then battery should come out from the system. The turn off signal can also be generated from the frequency. The threshold value of the frequency depends on the rating of the battery. Let us define, $P_{d g}$ as

$P_{d g}=P_{\text {MTrated }}+P_{\text {DGENrated }}-P_{\text {BSUrated }}$ 
Since the load demand plus losses are less than of $P_{d g}$, the battery can turn off. This can be detected from the frequency of the system with a threshold calculated from (1). For example, in case of DGEN, if the frequency is more than, that required to supply $(2 / 3) \times P_{d g}$, then battery can be disconnected. To accomplish this, the state machine as shown in Fig. 6, is developed.

The considered state machine has two states $\mathrm{x}_{1}$ and $\mathrm{x}_{2}$, two inputs $f_{1}$ and $f_{2}$ and output $D / \bar{B}$. The signal $f_{1}$ is generated when the droop frequency falls below a threshold frequency $49.72 \mathrm{~Hz}$. The signal $\mathrm{f}_{2}$ is generated when the droop frequency rises above $49.78 \mathrm{~Hz}$ (explained in Eq. 3). Initially, the state machine is idle and state $\mathrm{x}_{1} \mathrm{x}_{2}$ is 00 . When overloading occurs $f_{1}$ becomes 1 while $f_{2}$ remains 0 . The state moves to $x_{1} x_{2}=01$ and the output $D / \bar{B}$ becomes 1 . However, as soon as the battery is de-blocked, some transient causes $f_{1}$ to become 0 . However, it does not mean the overloading is removed. Therefore, state moves to $\mathrm{x}_{1} \mathrm{x}_{2}=11$ and the output still remains $D / \bar{B}$ $=1$. Once the transient is over and battery is firmly connected, $\mathrm{f}_{1}$ becomes 0 since frequency is higher than threshold value $49.8 \mathrm{~Hz}$. In this case, state will settle $\mathrm{x}_{1} \mathrm{x}_{2}=11$. When the overloading is removed then $\mathrm{f}_{2}$ becomes 1 and states moved to $\mathrm{x}_{1} \mathrm{x}_{2}=10$. The output become $D / \bar{B}=0$. The transient event will be taken care by debouncing and bouncing between $\mathrm{x}_{1} \mathrm{x}_{2}=10$ and 00 .

The state machine is realized by two JK flip-flop with the inputs given as [17]

$$
\begin{aligned}
& J_{X 1}=X_{2} \overline{f_{1}} \overline{f_{2}}+\overline{X_{2}} \overline{f_{1}} f_{2} \\
& K_{X 1}=X_{2} f_{1} \overline{f_{2}}+\overline{X_{2}} \overline{f_{1}} \overline{f_{2}} \\
& J_{X 2}=\overline{X_{1}} f_{1} \overline{f_{2}} \\
& K_{X 2}=X_{1} \overline{f_{1}} f_{2}
\end{aligned}
$$

where the hardware realization is shown in Fig. 7.

As the battery turns on, system frequency can be within specified band and BSU injects power at the same frequency. Thus, battery should synchronize with respect to $v_{t}$ (terminal voltage as shown in Fig. 1). For this purpose, simple phase locked loop (PLL) is designed, which is discussed briefly in Appendix B [15].

Example 2: Let us assume the MT in the microgrid of Fig. 1 has a rating of $250 \mathrm{~kW}$, while the DGEN is rated $500 \mathrm{~kW}$. Initially, the total load demand is $400 \mathrm{~kW}$ and both DGs are supplying power according to their rating in frequency droop control as shown in Fig. 8. At $t=5 \mathrm{~s}$, the load is increased to $800 \mathrm{~kW}$ and exceeds the total power rating of the DGs. It can be seen from Fig. 9 that frequency of MT hits to lower limit of the frequency band, which triggers the battery turn-on signal, as seen in Fig. 10. Thereafter, the battery starts supplying its rated power as seen in Fig. 8. The terminal voltage of the system is sinusoidal at BSU transition time, as seen in Fig. 11 and represents a smooth seamless operation when battery is pressed into supplying power.

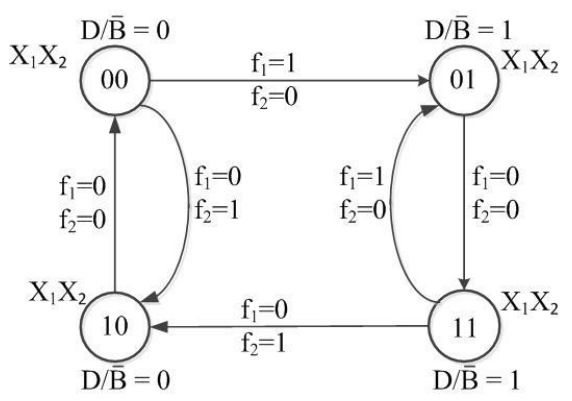

Fig.6. Developed state machine diagram.

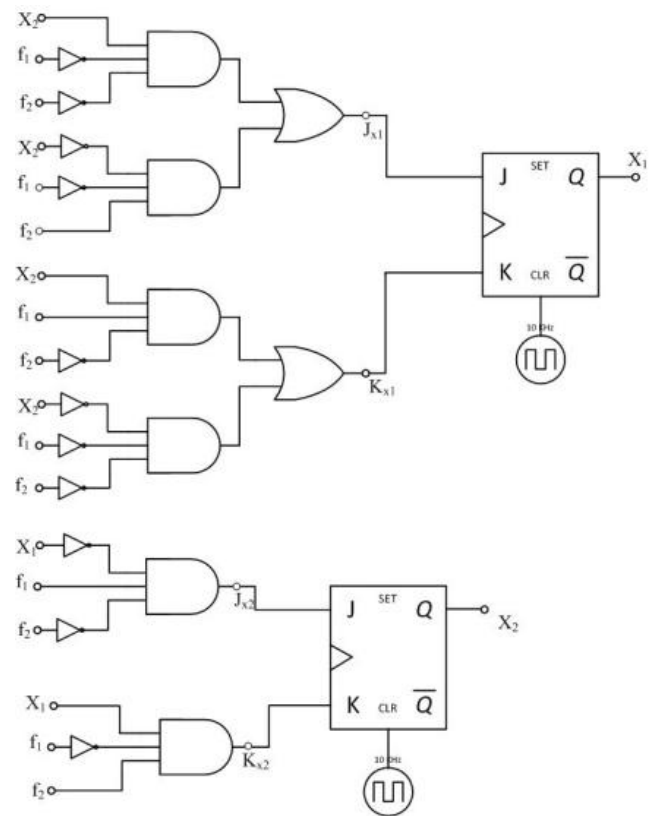

Fig.7. Logic circuit diagram for the developed BSU control.

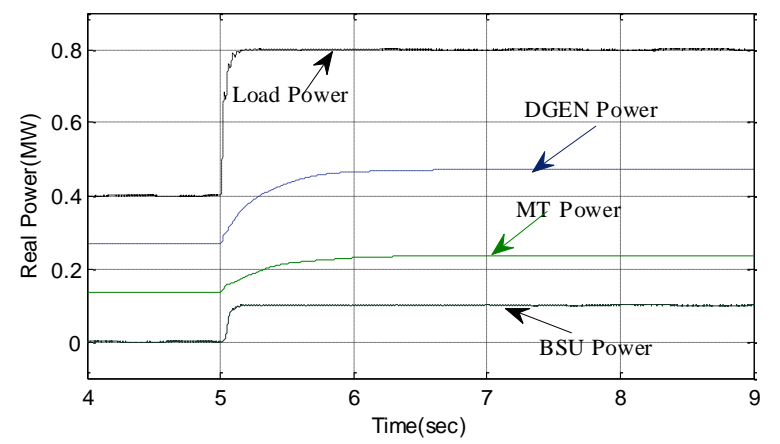

Fig. 8. Real power output of the DGs and load demand as battery connects.

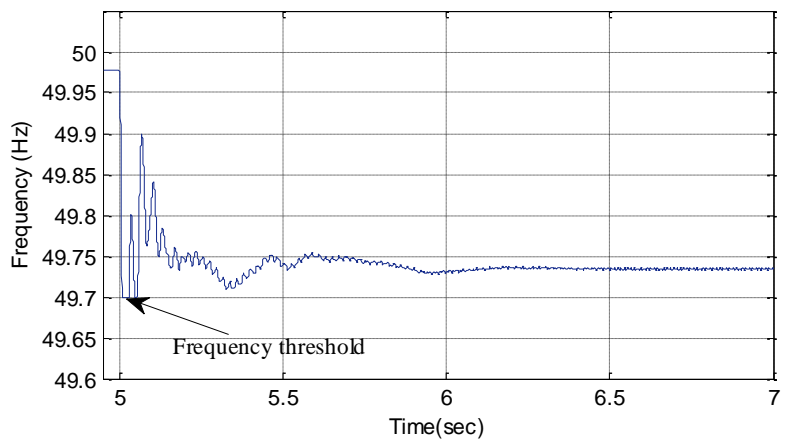

Fig. 9. Frequency variation of DG in autonomous microgrid. 


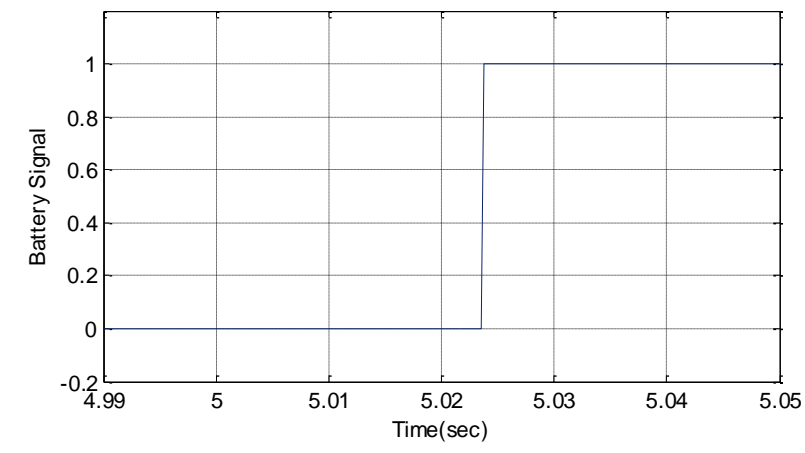

Fig. 10. Battery turn-on/off control signal.

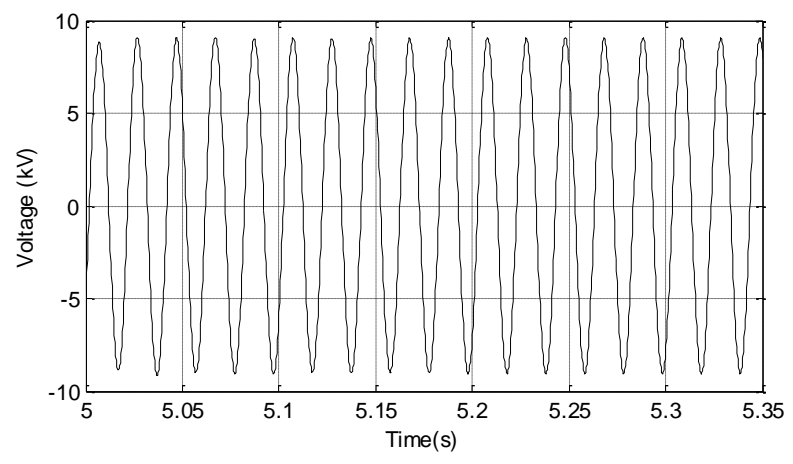

Fig. 11. BSU terminal voltage.

At $t=10 \mathrm{~s}$, the load demand reduces to $500 \mathrm{~kW}$ and it can be supplied only by the DGs. There is no requisite of the BSU as $P_{d g}$, the power supplied by both DGs, is

$$
P_{d g}=750-100=650 \mathrm{~kW}
$$

Therefore, the diesel generator power share is $433.33 \mathrm{~kW}$. The threshold value of the frequency can calculated from (1) using proper droop gain as

$$
f_{S}=50+\frac{0.0075 \times(0.5 \times 500-433.33)}{2 \pi}=49.78 \mathrm{~Hz}
$$

Therefore, the frequency less than the threshold value implies that the load demand has reduced below the total rating of the DGs and battery unit must be switched off. This is shown in Fig. 12. The power and frequency plots for this case are shown in Fig. 13 and 14, respectively. From these figures, it can be seen that the power supplied by battery is zero and other DGs start to supply the load demand in the frequency droop according to their rating. From Fig. 15, it can be seen that the terminal voltage of the system is also sinusoidal at the time of battery disconnection.

\section{CONCLUSIONS}

In this paper, a new control algorithm is proposed for battery storage unit to prevent the overloading of the DGs in an autonomous microgrid. This control algorithm facilitates the smooth transition and synchronization of the battery storage unit with an autonomous microgrid. The power sharing algorithm also works perfectly either when the battery is connected or disconnected. The developed control algorithm is validated through computer simulation using PSCAD/EMTDC.

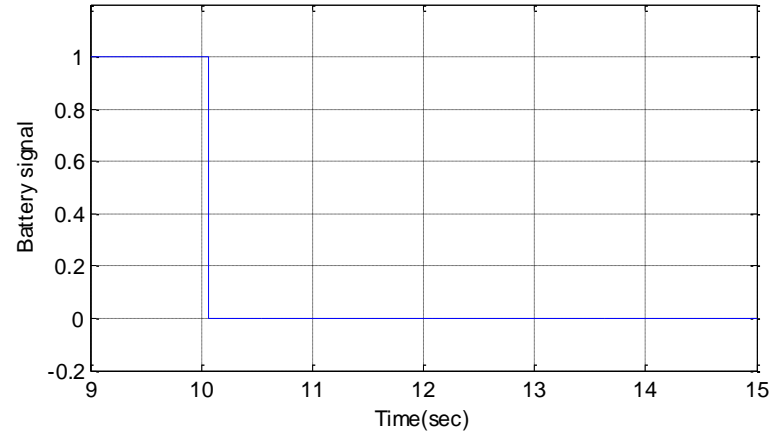

Fig. 12. Battery turn-on/off control signal.

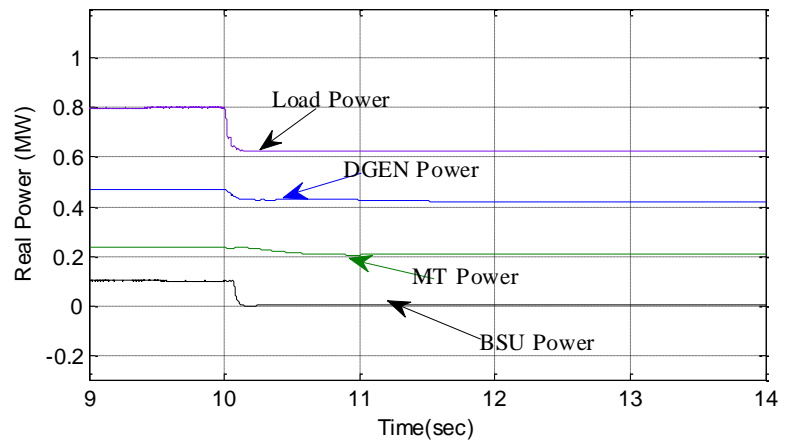

Fig. 13. Real power output of DGs and load demand as battery disconnects.

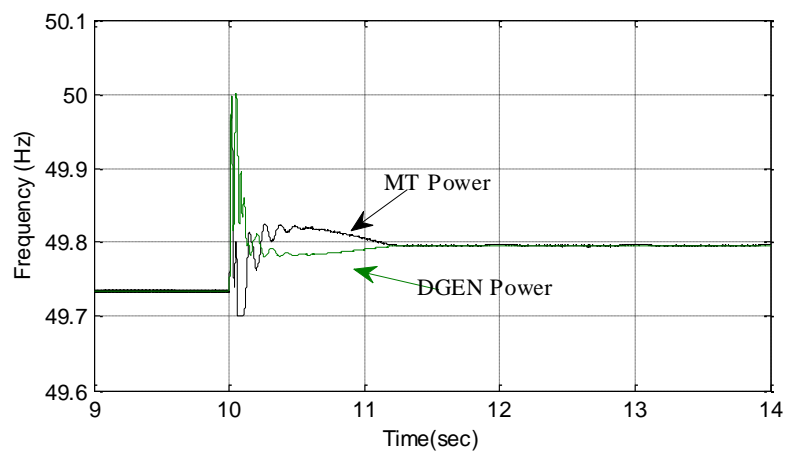

Fig. 14. Frequency variation of the DGs in autonomous microgrid.

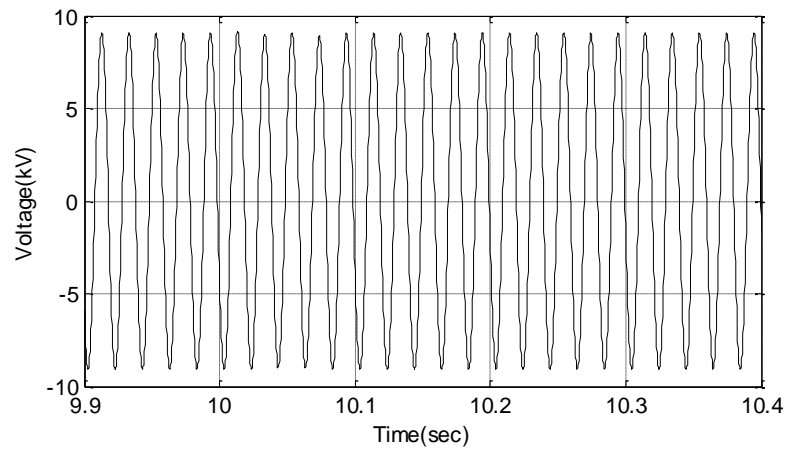

Fig. 15. BSU terminal voltage.

\section{REFERENCES}

[1] Mei Qiang, Wu Wei-yang and Xu Zhen-lin, "A Multi-Directional Power Converter for a Hybrid Renewable Energy Distributed Generation System with Battery Storage," Power Electronics and Motion Control Conference, no. 3, pp.1-5, Aug. 2006.

[2] Jinwei He, and Yun Wei Li, "An enhanced microgrid load demand sharing strategy," IEEE Trans. on Power Electronics, vol. 27, no. 9, pp. 3987-3995, Sep. 2012.

[3] P. Piagi, and R.H. Lasseter, "Autonomous Control of Microgrids," Proc. IEEE Power Engineering Society General Meeting, Montreal, June 2006. 
[4] K. Yukita, K. Ichiyanagi, Y. Goto and K. Hirose, "A Study of Electric Power Quality using Storage System in Distributed Generation," $9^{\text {th }}$ International Conference on Electrical Power Quality and Utilization, pp. 1-4, Oct. 2007.

[5] F. Katiraei, and M.R. Iravani, "Power management strategies for a microgrid with multiple distributed generation units," IEEE Trans. on Power System, vol. 21, no. 4, pp. 1821-1831, Nov. 2006.

[6] J.A.P. Lopes, C.L. Moreira and A.G. Madureira, "Defining control strategies for microgrids islanded operation," IEEE Trans. on Power Systems, vol. 21, no. 2, pp. 916-924, 2006.

[7] R. Lasseter and M. Erickson, "Integration of Battery Based Energy Storage Element in the CERTS Microgrid," University of Wisconsin Madison, October 2009.

[8] M. Goyal, A. Ghosh and F. Zare, "Power Sharing Control with Frequency Droop in a Hybrid Microgrid," IEEE Power and Energy Society General Meeting, 2013.

[9] R.H. Lasseter, "Dynamic models for micro-turbines and fuel cells," IEEE Power and Energy Society Summer Meeting, vol. 2, pp. 761-766, 2001.

[10] M.C. Chandorkar, D.M. Divan, and R. Adapa, "Control of parallel connected inverters in standalone ac supply systems," IEEE Trans. on Industrial Applications, vol. 29, no. 1, pp. 136-143, Jan./Feb. 1993.

[11] M. Reza, D. Sudarmadi, F.A. Viawan, W.L. Kling, and L. Van Der Sluis, "Dynamic stability of power systems with power electronic interfaced DG," Power Systems Conference and Exhibition, (PSCE), pp. 1423-1428, 2006.

[12] H. Gu, X. Guo and W. Wu, "Accurate power sharing control for inverter-dominated autonomous microgrid," International Power Electronics and Motion Control Conference (ECCE Asia), pp. 368-372, June 2012.

[13] A. Ghosh, "Performance study of two different compensating devices in a custom power park," Proc. IEE - Generation, Transmission \& Distribution, vol. 152, no. 4, pp. 521-528, 2005.

[14] R. Majumder, A. Ghosh, G. Ledwich and F. Zare, "Power management and power flow control with back-to-back converters in a utility connected microgrid," IEEE Trans. on Power Systems, vol. 25, no. 2, pp. 821-834, 2010.

[15] M. Goyal and A. Ghosh, "A Phase-Locked-Loop Design for the Smooth Operation of a Hybrid Microgrid," Australian Universities Power Engineering Conference (AUPEC), Tasmania, 2013.

[16] R. Majumder, S. Chakrabarti, G. Ledwich and A. Ghosh, "Control of battery storage to improve voltage profile in autonomous microgrid," IEEE Power and Energy Society General Meeting, pp. 1-8, 2011.

[17] G.S. Hope, Integrated Devices in Digital Circuit Design, John Wiley \& Sons, 1981.

[18] A. Ghosh and G. Ledwich, Power Quality Enhancement Using Custom Power Devices, Kluwer, 2002.

\section{APPENDIX A}

The technical parameters of the microgrid system shown in Fig. 1, are listed below.

Table I. Parameters of the diesel generator set

\begin{tabular}{|l|l|}
\hline System data & Value \\
\hline Rated voltage & $11 \mathrm{kV}$ \\
\hline Rated power & $433 \mathrm{~kW}, 500 \mathrm{kVA}$ \\
\hline Rated frequency & $50 \mathrm{~Hz}$ \\
\hline Rated speed & $1500 \mathrm{rpm}$ \\
\hline Reactance & Value (per unit) \\
\hline$X_{d}$ & 0.116 \\
\hline$X_{d}^{\prime}$ & $7.4 \times 10^{-3}$ \\
\hline$X^{\prime \prime}{ }^{\prime}$ & $2.94 \times 10^{-3}$ \\
\hline$X_{q}$ & $6.37 \times 10^{-3}$ \\
\hline$X^{\prime \prime}{ }_{q}$ & $5.24 \times 10^{-3}$ \\
\hline$X_{2}$ & 0.044 \\
\hline$X_{0}$ & $2.45 \times 10^{-3}$ \\
\hline Time constants & Value (ms) \\
\hline$t_{d}^{\prime}$ & 25 \\
\hline$t^{\prime \prime}$ & 25 \\
\hline$t_{d 0}^{\prime}$ & 368 \\
\hline$t_{a}$ & 4 \\
\hline & \\
\hline
\end{tabular}

Table II. Parameters of the DGs connected to the microgrid

\begin{tabular}{|c|c|}
\hline System Quantities & Values \\
\hline $\mathrm{DG}_{1}$ Feeder impedance & $R_{f l}=3.025 \Omega, L_{f I}=57.8 \mathrm{mH}$ \\
\hline $\mathrm{DG}_{2}$ Feeder impedance & $R_{f 2}=3.025 \Omega, L_{f 2}=57.8 \mathrm{mH}$ \\
\hline $\mathrm{DG}_{3}$ Feeder impedance & $R_{f 3}=3.025 \Omega, L_{f 3}=57.8 \mathrm{mH}$ \\
\hline DG Rated Power & MT: $250 \mathrm{~kW}$, DGEN: $500 \mathrm{~kW}$ \\
\hline \multicolumn{2}{|c|}{ Droop Coefficient (Frequency-Voltage) } \\
\hline$m_{1}$ & $0.015 \mathrm{rad} / \mathrm{MWs}$ \\
\hline$m_{2}$ & $0.0075 \mathrm{rad} / \mathrm{kWs}$ \\
\hline$n_{1}$ & $0.04 \quad \mathrm{kV} / \mathrm{MVAr}$ \\
\hline$n_{2}$ & $0.02 \quad \mathrm{kV} / \mathrm{MVAr}$ \\
\hline
\end{tabular}

APPENDIX B

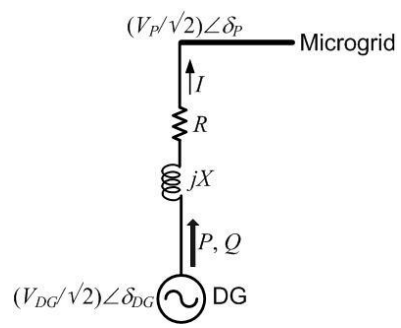

Fig. 16. Schematic of a DG connected to the microgrid.

Let the frequency of the terminal voltage be $\omega$. Then from Fig. 16, the instantaneous DG voltages with a peak of $V_{D G}$ and phase shifted by the terminal voltage by $\delta$ are given by [18]

$v_{D G a}=V_{D G} \sin \left(\omega t+\delta_{D G}\right)$

$v_{D G b}=V_{D G} \sin \left(\omega t+\delta_{D G}-120^{\circ}\right)$

$v_{D G c}=V_{D G} \sin \left(\omega t+\delta_{D G}+120^{\circ}\right)$

where $\delta=\delta_{D G}-\delta_{P}$.

The positive sequence of the desired DG voltages is

$$
\begin{aligned}
\mathbf{v}_{\text {DGa } 1}= & \frac{V_{D G}}{2}\left[\sin \left(\omega t+\delta_{p}\right) \cos \delta+\cos \left(\omega t+\delta_{p}\right) \sin \delta\right. \\
& \left.-j \cos \left(\omega t+\delta_{p}\right) \cos \delta+j \sin \left(\omega t+\delta_{p}\right) \sin \delta\right] \\
= & \frac{V_{D G}}{2}[(\alpha+j \beta) \cos \delta-(\beta-j \alpha) \sin \delta]
\end{aligned}
$$

where $\alpha=\sin \left(\omega t+\delta_{P}\right), \beta=-\cos \left(\omega t+\delta_{P}\right)$.

$$
\frac{V_{P}}{2}=\left|\mathbf{v}_{\text {Pa1 } 1}\right|, \alpha=\frac{\operatorname{Re}\left(\mathbf{v}_{\text {Pa1 }}\right)}{\left|\mathbf{v}_{\text {Pa1 } 1}\right|}, \beta=\frac{\operatorname{Im}\left(\mathbf{v}_{\text {Pa1 }}\right)}{\left|\mathbf{v}_{\text {Pa1 }}\right|}
$$

The positive sequence $\mathbf{v}_{\mathbf{D G} \text { a1 }}$ can be computed based on $\alpha$, $\beta, V_{D G}$ and $\delta$, of which the first two are obtained from (5). Note that the real power mainly depends on the angle difference and the reactive power mainly depends on the voltage magnitude. Therefore, two Proportional Integral (PI) controllers are used to calculate $V_{D G}$ and $\delta$ from reactive power and real power, respectively. As the negative sequence is the complex conjugate of the positive sequence and the zero sequence is assumed to be zero, three-phase instantaneous voltage of DG given in (4) is calculated by taking inverse symmetrical component transform. 